\title{
Osteocalcin, Skeletal Alkaline Phosphatase, and Bone Mineral Content in Very Low Birth Weight Infants: A Longitudinal Assessment
}

\author{
WILLIAM B. PITTARD, III, KITTY M. GEDDES, THOMAS C. HULSEY, AND BRUCE W. HOLLIS
}

Department of Pediatrics, Medical University of South Carolina, Charleston, South Carolina 29425

\begin{abstract}
Serum osteocalcin (Gla) and skeletal alkaline phosphatase (SAP) concentration both reflect osteoblast activity in the dynamic process of bone formation. To assess the relation in premature infants between change in bone mineral content (BMC) and both Gla and SAP serum concentration, we longitudinally measured BMC via photon absorptiometry and serum Gla and SAP concentration from birth to 16 wk in 20 very low birth weight infants. Serum total calcium, phosphorus, parathyroid hormone, and vitamin D metabolite concentrations were also monitored. All serum values were measured in the 20 mothers at delivery. Cord blood Gla concentrations were significantly $(p<0.03)$ greater than maternal levels, and by 1 wk had significantly $(p<0.001)$ increased from birth values. Total calcium, parathyroid hormone, phosphorus, and vitamin D concentrations remained in the normal range throughout the study. The increase in serum Gla concentrations, birth to $1 \mathrm{wk}$, were significantly correlated with the simultaneous increase in 1,25-dihydroxyvitamin $\mathrm{D}$ concentrations. The correlation between the change in BMC, however, over the first 4 mo of life and both Gla and SAP serum concentrations failed to reach statistical significance. Finally, a significant $(p<0.003)$ negative correlation was measured between serum Gla and SAP concentrations at wk 4 , and, although not significant, a consistently negative correlation was measured from 1-16 wk of age. These data demonstrate a 1,25-dihydroxyvitamin $D$ associated rise in neonatal serum Gla concentration during the 1st week after delivery, no significant correlation between the change in neonatal BMC over the first 4 mo of life and serum Gla or SAP concentration, and a consistent negative correlation between serum Gla and SAP concentrations. These data do not indicate that either serum Gla or SAP concentration is a reliable predictor for the change in bone mineral content of very low birth weight infants over the first 16 wk of life. (Pediatr Res 31: 181-185, 1992)
\end{abstract}

\section{Abbreviations}

Gla, osteocalcin

SAP, skeletal alkaline phosphatase

TAP, total alkaline phosphatase

BMC, bone mineral content

VLBW, very low birth weight $(<1500$ g)

PTH, parathyroid hormone

$1,25(\mathrm{OH})_{2} \mathrm{D}, 1,25$-dihydroxyvitamin $\mathrm{D}$

Received December 6, 1990; accepted October 2, 1991.

Correspondence: William B. Pittard, III, M.D., Children's Hospital, Medical University of South Carolina, 171 Ashley Ave., Charleston, South Carolina 29425.

Supported in part by Grant HD-22542 from the National Institute of Child Health and Human Development, National Institutes of Health, Bethesda, MD.
Gla is a noncollagenous, vitamin $\mathrm{K}$-dependent, calcium binding protein synthesized by the osteoblast. The serum concentration of Gla has been used as a marker for bone formation (1). In this regard, serum Gla arises from new cellular synthesis and secretion into plasma and does not reflect the release of bone matrix Gla during bone resorption (2). This protein is present in high serum concentration in rapidly growing animals and children (3-6). Because elevated concentrations of serum Gla in adults have been associated with increased serum alkaline phosphatase concentrations, Gla may represent a biochemical marker for developing neonatal BMC (7). A laboratory marker for bone mineralization would greatly facilitate the clinical management of VLBW infants (8). Therefore, a longitudinal study of VLBW infants from birth until age $16 \mathrm{wk}$ was used to test the hypothesis that serum Gla and SAP concentration may be used to predict developing neonatal BMC in VLBW infants.

\section{MATERIALS AND METHODS}

This investigation was approved by the Medical University of South Carolina Human Investigation Committee, and written parental consent was obtained for each patient before he or she entered the study. VLBW infants $(n=20)$ with a gestational age between 28 and 33 wk were chosen randomly within $12 \mathrm{~h}$ of birth, after the presence of minimal lung disease was clinically established. Gestational age was initially determined from the history of the mothers last menstrual period and was confirmed with a Ballard examination within $36 \mathrm{~h}$ of delivery (9). One- and 5-min Apgar scores were recorded.

During the first 2 wk of life, the premature infants were fed via orogastric tube an $84 \mathrm{~kJ} / 30 \mathrm{~mL}$ formula and were supplemented with i.v. glucose water. This formula contained 12.75 $\mathrm{mmol} / \mathrm{L}$ calcium, $12.58 \mathrm{mmol} / \mathrm{L}$ phosphorus, and no added vitamin D (Ross Laboratories, Columbus, $\mathrm{OH}$ ). Vitamin D was given in a randomized fashion as an oral supplement of $8.5,10$, 15 , or $20 \mu \mathrm{g} / \mathrm{d}$ or $300,400,600$, or 800 equivalent $\mathrm{IU} / \mathrm{d}$ in a glycerol carrier. No additional vitamin D supplements were given. Eight of the 20 infants received parenteral fluid containing amino acids as well as calcium and phosphate salts for $10 \mathrm{~d}$ or less before reaching full enteral feeds $(100 \mathrm{~mL} / \mathrm{kg} / \mathrm{d})$. No lipid or vitamin D supplementation was given with this parenteral nutrition. Although the exact volume of formula intake per $\mathrm{kg}$ per $\mathrm{d}$ was not measured after hospital discharge, oral intake until discharge was recorded and used to derive mineral intakes from manufacturers' data sheets. Weight was determined at birth and biweekly with a standard balance scale (Detecto Scale Company, Webb City, MO).

Serum concentrations of total calcium, phosphorus, parathyroid hormone, and vitamin D metabolites, as well as Gla and both TAP and SAP, were determined weekly from birth (cord blood) until wk 4 and biweekly from wk 4 to 16 . These data were compared and correlated with the change in BMC determined with measurements at birth, and at 8 and 16 wk using 
photon absorptiometry. After reviewing the Gla concentrations and noting that the major serum concentration changes occurred between birth and $1 \mathrm{wk}$, the correlation between these changes and the changes in PTH and $1,25(\mathrm{OH})_{2} \mathrm{D}$ concentrations over this period was determined.

The serum components measured in the neonates were also measured and compared in peripheral blood serum collected immediately before delivery from the 20 mothers. Additionally, maternal serum Gla concentrations were compared with the infant's cord blood Gla concentrations.

Cord blood samples were collected using venipuncture from the fetal side of the placenta immediately after placental delivery, and peripheral venous blood specimens were collected at wk 1 , $2,3,4,6,8,10,12,14$, and 16 . The blood was taken directly to the laboratory and centrifuged, and the serum was removed and frozen $\left(-20^{\circ} \mathrm{C}\right)$ until it was analyzed. If the neonate developed more than minimal lung disease within the first $12 \mathrm{~h}$ of life, the infant was not enrolled in the study, and the cord and maternal blood serum specimens were discarded.

The serum Gla and SAP concentrations were measured using RIA and colorimetric methodology, respectively. The RIA for Gla used rabbit antibovine Gla antibody and ${ }^{125}$ I-labeled bovine Gla. Both specimen collection and handling and assay technique followed the procedure recommended by INCSTAR Corporation (Stillwater, MN). Normal adult values using this technique are $0.72 \pm 0.21 \mathrm{nmol} / \mathrm{L}$. SAP was measured with the method of Behr and Barnert (10). This procedure involves precipitating the SAP from serum using wheat germ lectin and then calculating the difference between total serum alkaline phosphatase measured before and after precipitation. The normal range for serum SAP in adults using this technique is $35-95 \mathrm{IU} / \mathrm{L}$. The vitamin $\mathrm{D}$ metabolites were quantitated using radioreceptor and competitive protein binding assays and/or HPLC as previously described (11). Normal 25-hydroxyvitamin D neonatal serum concentration using these techniques is $25-125 \mathrm{nmol} / \mathrm{L}$. The calcium and phosphorus values were determined using standard colorimetric techniques $(12,13)$. Midmolecule PTH was determined with RIA (14). Normal adult serum PTH concentration using this technique is $59 \pm 15 \mathrm{pmol} / \mathrm{L}$.

BMC was measured with the photon absorptiometric system (Lunar Radiation, Inc., Madison, WI), in which a collimated 3$\mathrm{mm}$ diameter photon beam from a low activity ${ }^{125} \mathrm{I}$ source was passed beneath the one-third distal radius of the right forearm (15-17). The bone mineral assessment was at the junction of the middle and distal thirds of the radius bone, which has been shown to have the least variation in mineral content (18). The use of this site minimizes the error generated by measuring slightly different bone sites throughout a longitudinal study. Measurements of BMC were made within the first $2 \mathrm{~d}$ of life and, subsequently, at 8 and 16 wk after delivery. Reproducibility (without repositioning the arm) for the five scans performed for each determination of BMC was reflected by a mean \pm SD coefficient of variation of $1.1 \pm 0.7$. The "repositioning error" determined by repeating measurements of BMC after repositioning the arm was small. The correlation coefficient between measurements before and after repositioning of the arm was 0.99 .

Associations between the dependent and independent variables at each time period were assessed with Pearson correlation coefficients, using an adjusted $p$ value of 0.005 as the probability of a type I error. This preserved the comparison-wise error rate of 0.05 . Differences in average Gla, SAP, and BMC values over time were determined by analysis of variance (or covariance where indicated), using the Bonferroni correction for multiple assessments. The $t$ test was used to assess the difference in maternal blood and infant cord blood Gla concentrations (paired $t$ test) and also to assess the difference in the Gla concentrations in those infants with Apgar scores $\leq 7$ and in those with scores of 8-10 (nonpaired $t$ test) at 1 and $5 \mathrm{~min}$, respectively.

\section{RESULTS}

The mean \pm SD gestational age and birth weight for the 20 premature infants were $31.1 \pm 1.3 \mathrm{wk}$ and $1245 \pm 162 \mathrm{~g}$, respectively. Mean \pm SD Apgar scores at 1 and 5 min were 6.3 \pm 2.4 and $7.3 \pm 2.1$, respectively. The increases in infant weights recorded throughout the study were consistent with previously reported normal values for 31-wk gestational age neonates (19). The average weekly calcium, phosphorus, and caloric intake (including any parenteral intake) from birth through $6 \mathrm{wk}$ of age (median age at discharge) is shown in Table 1.

Ten of the 20 VLBW infants had all 11 timed blood specimens collected over the 16-wk study. Five infants had one missing specimen. Three had two missing specimens. One had three and one had four missing blood specimens. Similarly, although birth and 8-wk BMC measurements were obtained in all 20 neonates, the 16-wk BMC measurement was obtained in only 13 of 20 .

The serum total calcium, phosphorus, $\mathrm{PTH}$, and vitamin D metabolite data collected are shown in Table 2. Table 3 shows the serum Gla and both TAP and SAP concentrations measured at each time assessed. TAP and SAP concentrations significantly $(p<0.001)$ increased from birth to wk 1 . After wk 1 , there were no significant changes in the serum concentration of either parameter (Fig. 1). Table 3 also shows the BMC measured at birth, and at 8 and $16 \mathrm{wk}$. Maternal serum data are shown in Table 4.

The cord blood Gla concentrations were significantly $(p<$ 0.03 ) greater than the maternal concentrations. There was not, however, a significant correlation $(r=0.3464, p=0.173)$ between the maternal and cord blood Gla values.

Mean \pm SD cord blood Gla concentrations in infants with 1min Apgar scores $\leq 7(0.45 \pm 0.41 \mathrm{nmol} / \mathrm{L}, n=12)$ were not significantly $(p=0.6)$ different from those with scores of 8 to 10 $(0.59 \pm 0.67 \mathrm{nmol} / \mathrm{L}, n=8)$. Similarly, there was no statistically significant difference in the measured Gla concentrations between neonates with 5-min Apgar scores $\leq 7$ versus those with scores of 8 to 10 .

A significant $(p<0.001)$ increase in the neonatal serum Gla and $1,25(\mathrm{OH})_{2} \mathrm{D}$ concentration but not PTH concentration $(p$ $<0.07)$ from birth to age 1 wk was measured. There were no significant changes in Gla values after wk 1 (Fig. 2). The birth to 1 wk change in Gla concentration was significantly correlated with the change in $1,25(\mathrm{OH})_{2} \mathrm{D}$ concentration $(r=0.606, p<$ $0.008)$ but not with the change in PTH concentration $(r=0.164$, $p=0.52$ ) over the same time period.

The correlation between the absolute measured values for SAP and Gla $(n=20)$ was significant $(p<0.003)$ and negative $(r=$ -0.640 ) on wk 4 . Finally, although not all significant, the correlations between Gla and TAP and SAP concentrations from wk 1 through 16 were all negative. TAP and SAP serum concentration correlations with Gla levels throughout the first 4 mo of life are shown in Table 5.

There were no statistically significant associations between change in BMC and absolute Gla values or changes in serum Gla concentrations measured in any time period (first $8 \mathrm{wk}$, second $8 \mathrm{wk}$, or total study period). Similarly there were no statistically significant associations between change in BMC and absolute values or changes in serum alkaline phosphatase (TAP or SAP) concentrations measured at any time period.

Using the maternal serum data, there was not a significant correlation between Gla and SAP concentrations $(r=0.003, p$ $=0.9$ ). Further, only the correlation between maternal Gla and $1,25(\mathrm{OH})_{2} \mathrm{D}$ approached significance $(r=0.389, p=0.12)$.

Finally, using the infant data, there was not a significant correlation between serum Gla or alkaline phosphatase (SAP or TAP) and phosphorus, total calcium, $1,25(\mathrm{OH})_{2} \mathrm{D}$, or PTH at any time assessed. The infant 25 -hydroxyvitamin $\mathrm{D}$ concentrations indicated vitamin $\mathrm{D}$ sufficiency at each time assessed in all infants with no serum measurement less than $10 \mathrm{ng} / \mathrm{mL}$ except 
Table 1. Average weekly calcium, phosphorus, and caloric intake for first 6 wk of life in study infants*

\begin{tabular}{lcccccc}
\hline & Week 1 & Week 2 & Week 3 & Week 4 & Week 5 & Week 6 \\
\hline$n$ & 20 & 20 & 20 & 17 & 16 & 12 \\
Calcium $(\mathrm{mmol} / \mathrm{kg} / \mathrm{d})$ & $0.80 \pm .30$ & $1.93 \pm .35$ & $2.13 \pm .38$ & $2.18 \pm .20$ & $2.25 \pm .18$ & $2.33 \pm .18$ \\
Phosphorus $(\mathrm{mmol} / \mathrm{kg} / \mathrm{d})$ & $0.77 \pm .29$ & $1.90 \pm .32$ & $2.10 \pm .39$ & $2.16 \pm .23$ & $2.20 \pm .15$ & $2.29 \pm .19$ \\
Calories $(\mathrm{kcal} / \mathrm{kg} / \mathrm{d})$ & $66 \pm 11$ & $105 \pm 14$ & $113 \pm 16$ & $115 \pm 10$ & $119 \pm 9$ & $122 \pm 10$ \\
\hline
\end{tabular}

$*$ Mean \pm SD

Table 2. Infant serum concentrations*

\begin{tabular}{|c|c|c|c|c|c|c|}
\hline \multirow[b]{2}{*}{ Age (wk) } & \multirow[b]{2}{*}{$n$} & \multirow{2}{*}{$\begin{array}{l}\text { Total cal- } \\
\text { cium } \\
(\mathrm{mmol} / \mathrm{L})\end{array}$} & \multirow[b]{2}{*}{$\begin{array}{l}\text { Phosphorus } \\
\text { (mmol/L) }\end{array}$} & \multirow[b]{2}{*}{$\begin{array}{c}\text { PTH } \\
(\mathrm{pmol} / \mathrm{L})\end{array}$} & \multicolumn{2}{|c|}{ Vitamin D metabolite } \\
\hline & & & & & $\begin{array}{c}25(\mathrm{OH}) \mathrm{D} \dagger \\
(\mathrm{nmol} / \mathrm{L})\end{array}$ & $\begin{array}{c}1,25(\mathrm{OH})_{2} \mathrm{D} \\
(\mathrm{pmol} / \mathrm{L}) \\
\end{array}$ \\
\hline 0 & 20 & $2.1 \pm 0.3$ & $1.8 \pm 0.5$ & $69.4 \pm 16.2$ & $40.2 \pm 18.3$ & $73.4 \pm 22.7$ \\
\hline 1 & 20 & $2.2 \pm 0.2$ & $2.2 \pm 0.4$ & $86.7 \pm 33.9$ & $63.7 \pm 22.5$ & $114.2 \pm 40.9$ \\
\hline 2 & 20 & $2.2 \pm 0.2$ & $2.2 \pm 0.2$ & $73.3 \pm 20.2$ & $83.6 \pm 42.8$ & $96.4 \pm 28.4$ \\
\hline 3 & 20 & $2.3 \pm 0.2$ & $2.2 \pm 0.2$ & $74.7 \pm 20.8$ & $92.9 \pm 59.4$ & $110.1 \pm 35.6$ \\
\hline 4 & 19 & $2.2 \pm 0.2$ & $2.2 \pm 0.2$ & $75.1 \pm 29.9$ & $87.9 \pm 58.1$ & $120.2 \pm 40.7$ \\
\hline 6 & 19 & $2.2 \pm 0.2$ & $2.1 \pm 0.2$ & $74.7 \pm 30.0$ & $85.4 \pm 57.5$ & $132.9 \pm 35.4$ \\
\hline 8 & 20 & $2.3 \pm 0.2$ & $1.9 \pm 0.2$ & $69.1 \pm 21.9$ & $89.7 \pm 70.6$ & $126.5 \pm 36.1$ \\
\hline 10 & 19 & $2.2 \pm 0.2$ & $1.9 \pm 0.3$ & $66.1 \pm 24.7$ & $80.7 \pm 70.5$ & $149.3 \pm 54.9$ \\
\hline 12 & 16 & $2.4 \pm 0.2$ & $2.0 \pm 0.2$ & $65.2 \pm 21.2$ & $80.8 \pm 76.9$ & $142.7 \pm 60.1$ \\
\hline 14 & 16 & $2.3 \pm 0.2$ & $2.0 \pm 0.1$ & $57.9 \pm 16.2$ & $80.4 \pm 66.6$ & $144.3 \pm 36.3$ \\
\hline 16 & 13 & $2.4 \pm 0.2$ & $1.9 \pm 0.2$ & $47.5 \pm 14.1$ & $84.4 \pm 55.4$ & $128.6 \pm 53.9$ \\
\hline
\end{tabular}

$*$ Mean $\pm \mathrm{SD}$

$\dagger 25$-hydroxyvitamin $\mathrm{D}$.

Table 3. Infant Gla, TAP and SAP concentrations, and BMC values*

\begin{tabular}{|c|c|c|c|c|c|}
\hline Age (wk) & $n$ & $\begin{array}{c}\text { Gla } \\
(\mathrm{nmol} / \mathrm{L})\end{array}$ & TAP (IU/L) & SAP $(I U / L)$ & $\mathrm{BMC}(\mathrm{g} / \mathrm{cm})$ \\
\hline 0 & 20 & $0.5 \pm 0.5$ & $64.9 \pm 22.2$ & $57.8 \pm 21.4$ & $0.055 \pm 0.01$ \\
\hline 1 & 20 & $3.1 \pm 1.4$ & $138.6 \pm 59.6$ & $92.0 \pm 31.6$ & \\
\hline 2 & 20 & $3.4 \pm 1.3$ & $140.5 \pm 33.8$ & $88.8 \pm 29.1$ & \\
\hline 3 & 20 & $3.6 \pm 1.6$ & $136.6 \pm 37.2$ & $99.5 \pm 35.5$ & \\
\hline 4 & 19 & $3.3 \pm 1.2$ & $133.6 \pm 53.3$ & $105.7 \pm 41.4$ & \\
\hline 6 & 19 & $3.0 \pm 1.3$ & $135.1 \pm 69.5$ & $115.4 \pm 68.9$ & \\
\hline 8 & 20 & $2.9 \pm 1.0$ & $126.6 \pm 60.2$ & $107.3 \pm 60.2$ & $0.059 \pm 0.02$ \\
\hline 10 & 19 & $2.6 \pm 1.3$ & $131.3 \pm 48.8$ & $115.9 \pm 45.4$ & \\
\hline 12 & 16 & $3.2 \pm 1.5$ & $124.8 \pm 40.0$ & $110.8 \pm 38.2$ & \\
\hline 14 & 16 & $2.7 \pm 1.1$ & $130.3 \pm 44.7$ & $114.4 \pm 40.0$ & \\
\hline 16 & 13 & $2.9 \pm 0.9$ & $107.9 \pm 35.9$ & $91.9 \pm 32.2$ & $0.085 \pm 0.01$ \\
\hline
\end{tabular}

$*$ Mean \pm SD.

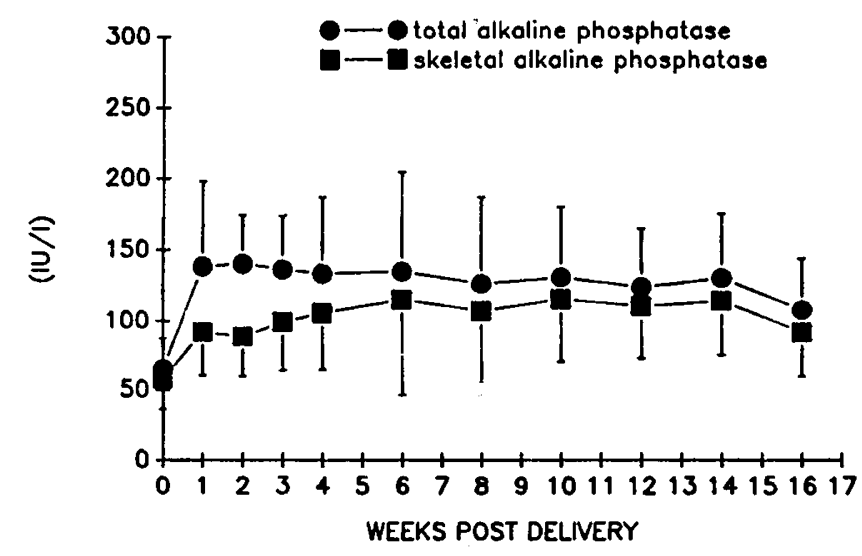

Fig. 1. Serum TAP and SAP concentrations in very low birth weight infants $(n=20)$ over the first $16 \mathrm{wk}$ of life.

in cord blood (Table 2). The vitamin D data are further described in a separate report (20).

\section{DISCUSSION}

Although the precise function of Gla in bone synthesis is not clear, certain characteristics of this protein are well described. It
Table 4. Maternal serum concentrations at delivery $(n=20)^{*}$

\begin{tabular}{lc}
\hline Total calcium $(\mathrm{mmol} / \mathrm{L})$ & $2.1 \pm 0.4$ \\
Phosphorus $(\mathrm{mmol} / \mathrm{L})$ & $1.4 \pm 0.8$ \\
PTH (pmol/L) & $68.4 \pm 22.5$ \\
25-Hydroxyvitamin D $(\mathrm{nmol} / \mathrm{L})$ & $48.0 \pm 19.3$ \\
1,25-(OH) $)_{2} \mathrm{D}(\mathrm{pmol} / \mathrm{L})$ & $120.5 \pm 42.3$ \\
Gla $(\mathrm{nmol} / \mathrm{L})$ & $0.2 \pm 0.2$ \\
Bone alkaline phosphatase $(\mathrm{IU} / \mathrm{L})$ & $9.0 \pm 6.7$ \\
\hline
\end{tabular}

$*$ Mean \pm SD.

is synthesized by osteoblasts and its synthesis is, at least in part, regulated by $1,25(\mathrm{OH})_{2} \mathrm{D}(21-24)$. Because of this, Gla may play a role in the action of vitamin $\mathrm{D}$ on bone metabolism. Further, serum Gla concentration correlates broadly with total serum alkaline phosphatase in patients with metabolic bone disease characterized by increased bone turnover (7) and with histomorphometric indices of bone formation (1). Therefore, the osteoblastic synthesis of Gla and its serum concentration is thought to indicate bone formation.

In this study, the change in BMC (minearlization) during the first 16 wk of life was not significantly correlated with serum Gla or alkaline phosphatase concentration. Furthermore, despite theoretically being more closely associated with bone formation, 


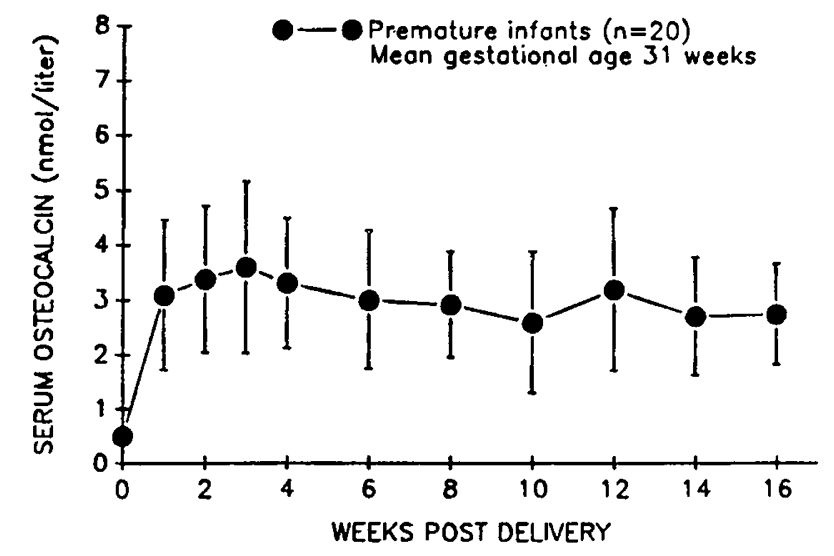

Fig. 2. Longitudinal measurement of serum Gla in VLBW infants over the first $16 \mathrm{wk}$ of life.

Table 5. Correlation coefficients of serum Gla vs SAP and TAP at each time point sampled

\begin{tabular}{|c|c|c|c|c|c|}
\hline \multirow[b]{2}{*}{ Week } & \multirow[b]{2}{*}{$n$} & \multicolumn{2}{|c|}{ Gla vs SAP } & \multicolumn{2}{|c|}{ Gla vs TAP } \\
\hline & & $r$ & $p^{*}$ & $r$ & $p^{*}$ \\
\hline 0 & 20 & 0.583 & 0.014 & 0.573 & 0.013 \\
\hline 1 & 20 & -0.134 & 0.573 & -0.361 & 0.118 \\
\hline 2 & 20 & -0.213 & 0.367 & -0.316 & 0.175 \\
\hline 3 & 20 & -0.342 & 0.139 & -0.414 & 0.070 \\
\hline 4 & 19 & -0.646 & 0.003 & -0.569 & 0.011 \\
\hline 6 & 19 & -0.460 & 0.047 & -0.481 & 0.037 \\
\hline 8 & 20 & -0.537 & 0.015 & -0.557 & 0.011 \\
\hline 10 & 19 & -0.289 & 0.230 & -0.267 & 0.268 \\
\hline 12 & 16 & -0.328 & 0.214 & -0.300 & 0.358 \\
\hline 14 & 16 & -0.509 & 0.044 & -0.497 & 0.050 \\
\hline 16 & 13 & -0.319 & 0.288 & -0.241 & 0.428 \\
\hline
\end{tabular}

${ }^{*} p \leq 0.005$ constitutes statistical significance.

serum SAP did not correlate with change in neonatal BMC better than serum TAP concentrations.

The previously reported reduction in serum Gla concentration in full-term neonates with low Apgar scores at 1 min was not observed in this study of premature babies (4). Infants with Apgar scores $\leq 7$ at one and/or $5 \mathrm{~min}$ had serum Gla concentrations similar to those with Apgar scores of 8-10.

The maternal serum Gla concentrations measured in peripheral blood drawn immediately before delivery were consistent with previous reports from both animal and human studies $(25$, 26). The Gla concentrations were low. Two of the 20 were below the lower detection limit $(0.034 \mathrm{nmol} / \mathrm{L})$ of the RIA, and the mean \pm SD serum concentration for all 20 women was $0.2 \pm$ $0.2 \mathrm{nmol} / \mathrm{L}$. The low maternal Gla serum concentration observed throughout pregnancy has been postulated to reflect both placental clearance (25) and decreased osteoblast production (26). A definitive explanation awaits further study.

Throughout the last trimester of gestation, the fetus maintains a serum calcium concentration (both ionized and total) greater than maternal levels. This maternal-fetal relationship is thought to be maintained by an active placental calcium pump and may, in part, explain the increased maternal PTH and $1,25(\mathrm{OH})_{2} \mathrm{D}$ serum concentrations of late pregnancy (27-29).

At delivery, the fetus encounters an abrupt decrease in calcium intake. To maintain serum calcium levels, a neonatal endocrine response including an increase in both $1,25(\mathrm{OH})_{2} \mathrm{D}$ and PTH levels is thought to occur $(30,31)$. In this study, a significant $(p$ $<0.001)$ increase in $1,25(\mathrm{OH})_{2} \mathrm{D}$ was measured, but the simultaneous increase in PTH was not significant $(p<0.07)$ and the total calcium concentrations at $1 \mathrm{wk}$ were in the normal range. Although serum total calcium values may be influenced by such factors as total protein concentration, there is a good correlation between total and ionized calcium in the newborn.
Total calcium as well as PTH concentrations may have varied during the 1st wk and returned to normal before the 7-d blood specimen was drawn. However, based on these data, the physiologic drive for this calcitriol increase is not clear and the possibility of a noncalcium driven neonatal vitamin $\mathrm{D}$ response is presented. Further study of neonatal serum Gla and each of these serum parameters with more data points during the first 7 $\mathrm{d}$ of life will undoubtedly shed light on this issue.

The increase in serum Gla concentration from birth to age 1 wk was significantly $(r=0.606, p<0.008)$ associated with the simultaneous increase in $1,25(\mathrm{OH})_{2} \mathrm{D}$. Although this relation has not previously been reported in VLBW neonates, it was not unexpected, inasmuch as $1,25(\mathrm{OH})_{2} \mathrm{D}$ has been shown to be a stimulator of Gla production in both human and animal studies $(22,24)$.

The reported changes in neonatal serum Gla concentration after delivery have been inconsistent $(24,32)$. Loughead et al. (32) reported during the first $24 \mathrm{~h}$ of life a significant $(p<0.03)$ inverse correlation between serum Gla and PTH concentrations, but did not measure $1,25(\mathrm{OH})_{2} \mathrm{D}$ levels. In contrast, Delmas et al. (24) reported a significant correlation between pooled $1,25(\mathrm{OH})_{2} \mathrm{D}$ and Gla concentrations over the first $5 \mathrm{~d}$ of life, but did not measure PTH concentrations. Interestingly, the cord blood Gla values reported by Delmas et al. were less than $30 \%$ of those in the study of Loughead et al. Both of these investigators studied healthy, full-term newborns.

The study of Delmas et al. (24) also included 10 low-birthweight infants. The cord blood Gla concentrations in their lowbirth-weight infants were similar to the values in the VLBW infants of this report. In this evaluation, the changes in $1,25(\mathrm{OH})_{2} \mathrm{D}$ and Gla during the $1 \mathrm{st}$ wk after delivery were significantly $(p<0.01)$ correlated, but neither the absolute $1,25(\mathrm{OH})_{2} \mathrm{D}$ nor PTH values were significantly correlated with the absolute Gla values at birth or age $1 \mathrm{wk}$. Further, the change in PTH values over the 1st wk of life did not correlate significantly $(r=-0.164, p=0.52)$ in this study with the change in Gla values.

As in the study of Delmas et al. (24), the neonatal Gla values in this study were significantly $(p<0.03)$ greater than the values measured in maternal blood at delivery. Similarly, there was not a significant correlation between maternal and cord blood concentrations. Maternal values were not measured in the study of Loughead et al. (32).

The data reported here indicate 1$)$ a rise in serum Gla concentration during the 1st wk after delivery significantly $(p<0.01)$ correlated with the simultaneous rise in $\left.1,25(\mathrm{OH})_{2} \mathrm{D} ; 2\right)$ no significant correlation between Gla and PTH serum concentrations; 3) no significant correlation between serum Gla concentration and total calcium or phosphorus concentration; 4) a consistently negative correlation between serum Gla and both TAP and SAP concentrations, reaching significance $(p<0.003)$ only for SAP at wk 4; and 5) no significant correlation between the longitudinal change in BMC and Gla or alkaline phosphatase concentrations. Thus, these data do not support the contention that serum Gla or alkaline phosphatase concentration is a biochemical marker for change in the BMC of VLBW infants during the first 4 mo of life.

Acknowledgment. The authors thank Ross Laboratories, Columbus, $\mathrm{OH}$, for providing the $84 \mathrm{~kJ} / 30 \mathrm{~mL}$ formula without added calcitriol.

\section{REFERENCES}

1. Hauschka P 1986 Osteocalcin: the vitamin $\mathrm{K}$-dependent $\mathrm{Ca}^{2+}$-binding protein of bone matrix. Haemostasis 16:258-272

2. Price $P$, Williamson $M$, Lothringer $J 1981$ Origin of the bone $\tau$ carboxyglutamic acid-containing protein found in plasma and its clearance by kidney and bone. J Biol Chem 256:12760-12766

3. Price P, Williamson M 1981 Effects of warfarin on bone: studies on the vitamin D-dependent protein of rat bone. J Biol Chem 265:12754-12759 
4. Cole D, Carpenter T, Gundberg C 1985 Serum osteocalcin levels in children with metabolic bone disease. J Pediatr 106:770-776

5. Gundberg C, Lian J, Gallop P 1983 Measurements of gamma carboxyglutamate and circulating osteocalcin in normal adults and children. Clin Chim Acta 128:1-8

6. Kruse K, Kracht U 1986 Evaluation of serum osteocalcin as an index of altered bone metabolism. Eur J Pediatr 145:27-33

7. Price P, Parthemore J, Deftos L 1980 A new biochemical marker for bone metabolism. J Clin Invest 66:878-883

8. James J, Congdon P, Truscott J, Horsman A, Arthur R 1986 Osteopenia of prematurity. Arch Dis Child 62:871-876

9. Ballard J, Novak K, Driver M 1979 A simplified score for assessment of fetal maturation of newly born infants. J Pediatr 95:769-774

10. Behr W, Barnert $J 1986$ Quantification of bone alkaline phosphatase in serum by precipitation with wheat germ lectin: a simplified method and its clinical plausibility. Clin Chem 32:1960-1966

11. Hollis B, Pittard W 1984 Evaluation of the total fetomaternal vitamin D relationship at term: evidence for racial differences. J Clin Endocrinol Metab 59:652-657

12. Sarker B, Chauhan U 1967 A new method for determining micro quantities of calcium in biological materials. Anal Biochem 20:155-166

13. Goldenburg H, Fernandez A 1966 Simplified method for the estimation of inorganic phosphorus in body fluids. Clin Chem 12.871-882

14. Roos B, Lindall A, Aron D, Orf J, Yoon M, Huber B, Pensky J, Ells J, Lambert P 1981 Detection and characterization of small midregion parathyroid hormone fragment(s) in normal and hyperparathyroid glands and sera by immunoextraction and region-specific radioimmunoassays. J Clin Endocrinol Metab 53:709-721

15. Greer F, Lane J, Weiner S, Mazess R 1983 An accurate and reproducible absorptiometric technique for determining bone mineral content in newborn infants. Pediatr Res 17:259-262

16. Pittard W, Geddes K, Sutherland S, Miller M, Hollis B 1990 Longitudinal changes in the bone mineral content of term and premature infants. Am J Dis Child 144:36-40

17. Pittard W, Geddes K, Hollis B 1988 Correlation of bone mineralization in the radius and humerus of well premature neonates over the first four months of life. Bone Miner 5:69-76

18. James J, Truscott J, Congdon P, Horsman A 1986 Measurement of bone mineral content in the human fetus by photon absorptiometry. Early Hum Dev 1:169-181

19. Shaffer S, Avimiro C, Anderson J, Hall T 1987 Postnatal weight changes in low birthweight infants. Pediatrics 79:702-705

20. Pittard W, Geddes K. Hulsey T, Hollis B 1991 How much vitamin D for neonates? Am J Dis Child 145:1147-1149

21. Price P, Baukol S 1980 1,25-Dihydroxyvitamin $D_{3}$ increases synthesis of the vitamin $\mathrm{K}$-dependent bone protein by osteosarcoma cells. J Biol Chem 255:11660-11663

22. Price P, Baukol S 1981 1,25-Dihydroxyvitamin $D_{3}$ increases serum levels of the vitamin K-dependent bone protein. Biochem Biophys Res Commun 99:928-935

23. Gundberg C, Cole D, Lian J, Reade T, Gallop P 1983 Serum osteocalcin in the treatment of inherited rickets with 1,25-dihydroxyvitamin $D_{3}$. J Clin Endocrinol Metab 56:1063-1067

24. Delmas P, Glorieux, F, Delvin E, Salle B, Melki I 1987 Perinatal serum bone Gla-protein and vitamin D metabolites in preterm and full term neonates. J Clin Endocrinol Metab 65:588-591

25. Rodin A, Duncan A, Ovartero H, Pistofidis G, Mashiter G, Whitakr K, Crook D, Stevenson J, Chapman M, Fogelman I 1989 Serum concentrations of alkaline phosphatase isoenzymes and osteocalcin in normal pregnancy. $\mathbf{J}$ Clin Endocrinolol Metab 68:1123-1127

26. Farrugia W, Fortune C, Heath J, Caple I, Wark J 1989 Osteocalcin as an index of osteoblast function during and after ovine pregnancy. Endocrinology 125:1705-1710

27. Kliegman R, Wald M 1986 Problems in metabolic adaptation: Glucose, calcium and magnesium. In: Klaus M, Fanaroff A (eds) Care of the HighRisk Neonate. WB Saunders, Philadelphia, pp 220-238

28. Jacques S, Salle B 1987 Calcium, phosphorus, magnesium and vitamin D. In: Stern L, Vert P (eds) Neonatal Medicine. Year Book Medical Publishers, New York, pp $831-848$

29. Mimouni F, Tsang R 1987 Disorders of calcium and magnesium metabolism. In: Fanaroff A, Martin R, Neonatal Perinatal Medicine. CV Mosby, Washington, DC, pp 1077-1093

30. Steichen J, Tsang R, Gratton T, Hamstra A, DeLuca H 1980 Vitamin D homeostasis in the perinatal period. N Engl J Med 302:315-319

31. Tsang R, Chen I, Friedman M 1975 Parathyroid function in infants of diabetic mothers. J Pediatr 86:399-404

32. Loughead J, Mimouni F, Ross R, Tsang R 1990 Postnatal changes in serum osteocalcin and parathyroid hormone concentrations. J Am Coll Nutr 9:358362 